Journal of the Magnetics Society of Japan Vol. 15 Supplement, No. S2 (1991)

(C) 1991 by The Magnetics Society of Japan

\title{
THE CHARACTERISTICS OF HIGH COERCIVITY RIGID DISK WITH PARTICULATE BA-FERRITE AND $\alpha$-FE
}

\author{
Akinori NISHIZAWA, Tsuneo KAGOTANI, Junichi SATOH, Kenji YOKOYAMA, \\ Keiji KOGA and Yasumichi TOKUOKA \\ R\&D Center, TDK Corp. \\ 113, Nenei, Saku, Nagano, 385, Japan
}

\begin{abstract}
The objective of this study is to develop rigid disks which have higher recording density and are more reliability by using barium ferrite or $\alpha-\mathrm{Fe}$ particles. The produced disks had more than $1000 \mathrm{Oe}$ of the coercivity and the thicknesses of the magnetic layers were less than $0.2 \mu \mathrm{m}$. The surface roughness of the produced disks were more smooth than those of conventional rigid disks. The head flying height could be reduced less than $0.1 \mu \mathrm{m}$, and the disks had high recording density more than $30 \mathrm{kFCI}$. CSS (Contact-StartStop) durability of the disks performed more than 20,000 cycles. Moreover, the produced disks had low friction coefficients.
\end{abstract}

\section{INTRODUCTION}

In recent years, digital magnetic recording drive systems have been developed rapidly. Therefore, larger capacity, faster access time and smaller drive size have been actively studied. In magnetic recording media, old products have been replaced by new ones with additional values.

In small magnetic recording media, the particulate disks with oxide powders, for example $\mathrm{Co}-\gamma-$ $\mathrm{Fe}_{2} \mathrm{O}_{3}$, have been replaced by thin film types produced by sputtering or plating methods, and these show excellent characteristics in read/write properties. In the recording heads, MIG (Metal In Gap) and thin film head have been used with the higher coercivity media. The spacing between a flying head and the media has become shorter. Therefore, the reliability of media should be more important.

The particulate rigid disks with $\mathrm{Co}-\gamma-\mathrm{Fe}_{2} \mathrm{O}_{3}$ powder are excellent in durability, but have relatively lower recording density because of its lower coercivity and the surface roughness. Magnetic particles with high coercivity, such as barium ferrite or $\alpha-\mathrm{Fe}$ particles, have not prevailed in rigid media market, yet.

In this paper, the possibility of the rigid disks with barium ferrite or $\alpha-F e$ particles for high density recording media are described.

\section{EXPERIMENT}

The properties of used hexagonal barium ferrite and $\alpha-F e$ ferromagnetic powders prepared are shown in Table 1. The easy axis of barium ferrite is perpendicular to the plane of the particle [1].

These particles were dispersed in a resin binder with several additives. 3.5" diamond turned $\mathrm{Al}-\mathrm{Mg}$ alloy substrates exposed by chromate treatment were used. The magnetic paints with barium ferrite or $\alpha-$ Fe were coated on the substrates by spin coating method. The easy axes of the magnetic particles were oriented to the circumferential direction in the disk plane by a magnetic field. After that, disks were cured by heat treatment and the disk polishing was carried out. Finally, lubricant was coated on the disk surfaces.

Table 2 shows the magnetic properties of the disks. The coercivity of our specimen exhibited $1310-1360 \mathrm{Oe}$ and the thickness was $0.18-0.20 \mu \mathrm{m}$. Moreover, in table 2, the magnetic properties of the particulate disk with $\mathrm{Co}-\gamma-\mathrm{Fe}_{2} \mathrm{O}_{3}$ powder and the thin film media with $\mathrm{Co}-\mathrm{Pt}-\mathrm{Ni}, \mathrm{Co}-\mathrm{Ni}-\mathrm{Cr}$ and $\mathrm{Co}-$ Ni-P alloys are shown in comparison. The thin film

Table 1 . The properties of magnetic particles

\begin{tabular}{|c|c|c|c|}
\hline $\begin{array}{l}\text { Magunetic } \\
\text { Material }\end{array}$ & $\begin{array}{c}\mathrm{H} \mathrm{C} \\
(\mathrm{Oe})\end{array}$ & $\begin{array}{c}\sigma \mathrm{s} \\
(\mathrm{emu} / \mathrm{g})\end{array}$ & $\begin{array}{c}\mathrm{BET} \\
\left(\mathrm{m}^{2} / \mathrm{g}\right)\end{array}$ \\
\hline Bariua Perrite & 941 & 52.9 & 31.9 \\
\hline$\alpha-\mathrm{Fe}$ & 1408 & 136.7 & 42.5 \\
\hline
\end{tabular}

Table 2. The magnetic properties of the disks

\begin{tabular}{|c|c|c|c|c|c|c|}
\hline \multicolumn{2}{|c|}{ Sample } & $\mathrm{H} \mathrm{C}$ & S & $s^{*}$ & $\mathrm{Bm}$ & $\delta$ \\
\hline Bariun Ferrite & \multirow{3}{*}{ Coated } & 1360 & 0.81 & 0.85 & 1280 & 0.200 \\
\hline$\alpha-F$ e & & 1310 & 0.84 & 0.72 & 2100 & 0.180 \\
\hline $\mathrm{Co}-\gamma-\mathrm{Fe}_{2} \mathrm{O}_{3}$ & & 650 & 0.83 & 0.64 & 1480 & 0.480 \\
\hline $\mathrm{Co}_{0}-\mathrm{Pt}-\mathrm{Ni}$ & \multirow{2}{*}{ Sputtered } & 1435 & 0. 78 & 0.87 & 10660 & 0.050 \\
\hline $\mathrm{Co}_{0} \mathrm{Ni}-\mathrm{Cr}$ & & 850 & 0.87 & 0.74 & 10180 & 0.049 \\
\hline $\mathrm{Co}_{0}-\mathrm{Ni}-\mathrm{P}$ & Plated & 945 & 0.76 & 0.86 & 12000 & o. 044 \\
\hline
\end{tabular}



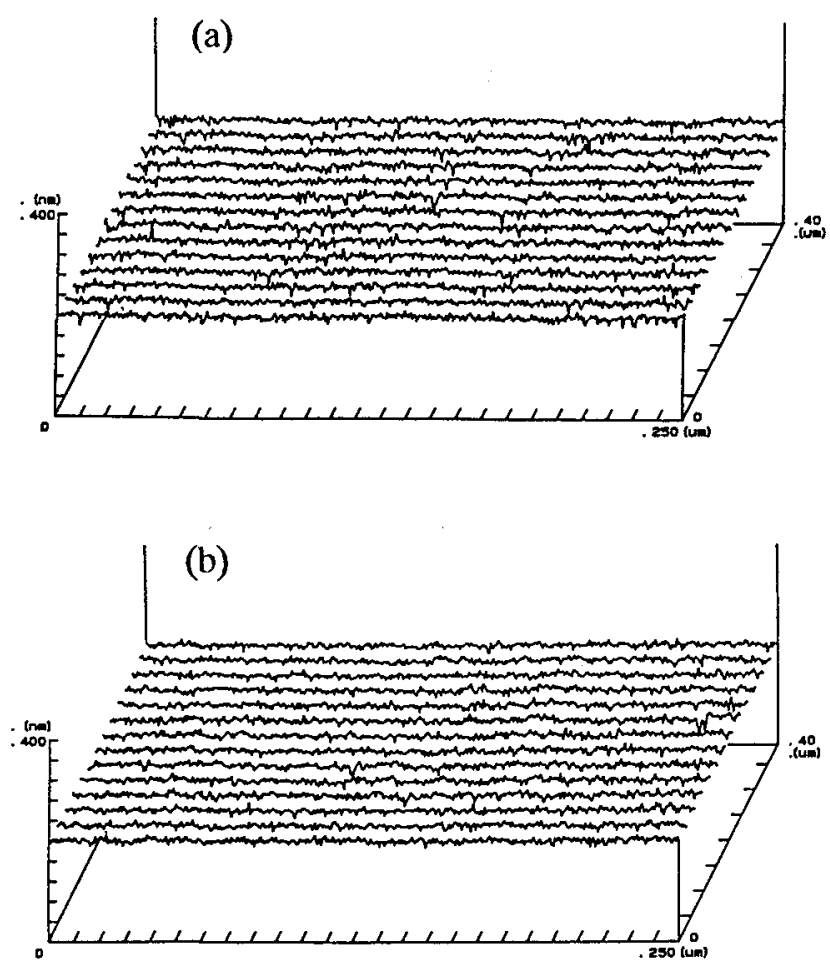

disks have large $\mathrm{Bm}$ because of the magnetic layer produced with only magnetic materials. $\mathrm{S}^{*}$ of the disks produced in this work and thin film media are much higher than that of the $\mathrm{Co}-\gamma-\mathrm{Fe}_{2} \mathrm{O}_{3}$ disk.

\section{RESULT}

\section{Head-Fly-Height Characteristics}

\section{1) Surface Roughness}

To obtain high recording density, the spacing between a flying head and a disk must be reduced. Therefore, surface topography of the disk is very important.

Table 3 shows the surface roughness ( $R a$, $\mathrm{Rmax}$ ) of the produced disks and the others in comparison. Fig.1 indicates the profiles of the disk surfaces measured by a three dimensional stylus instrument. The radius of stylus was $0.5 \mu \mathrm{m}$. As shown in these table and figure, the surface roughness ( $\mathrm{Ra}$ ) of the produced media were $33-35 \mathrm{~A}$, therefore, the surfaces of these disks are more smooth than those of the others.

Fig. 2 shows the number of the peaks on the

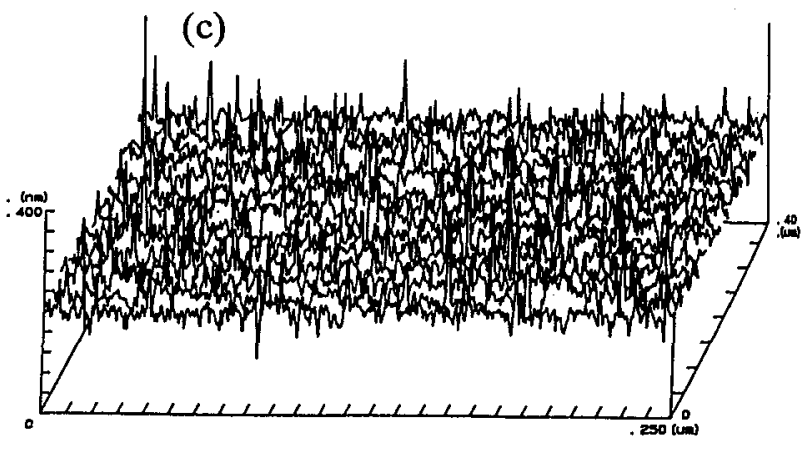

(d)

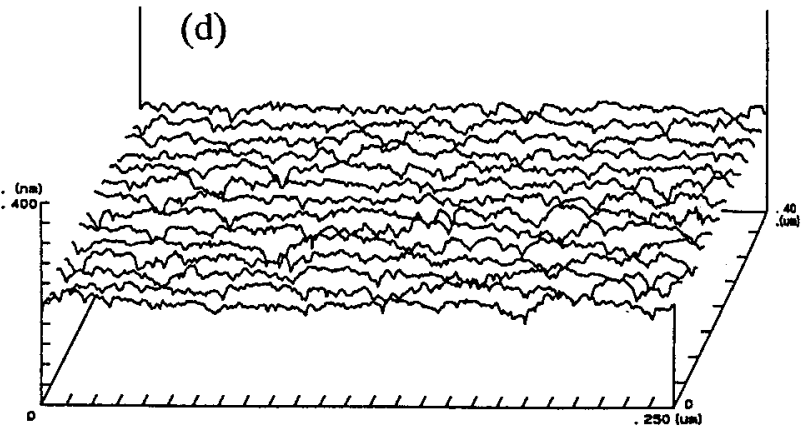

(e)

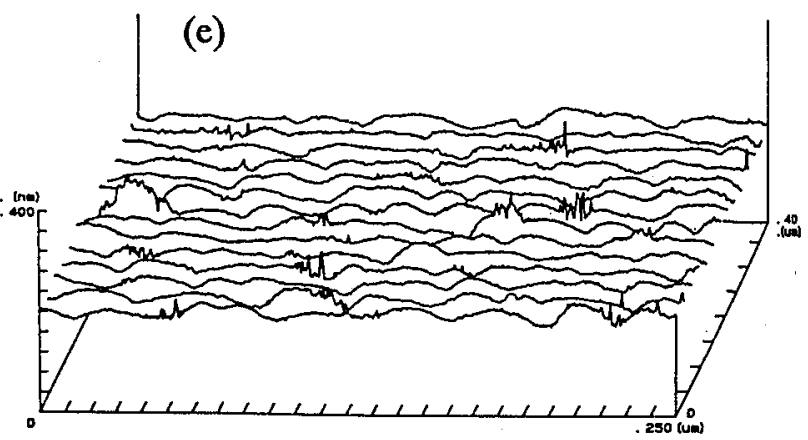

(f)

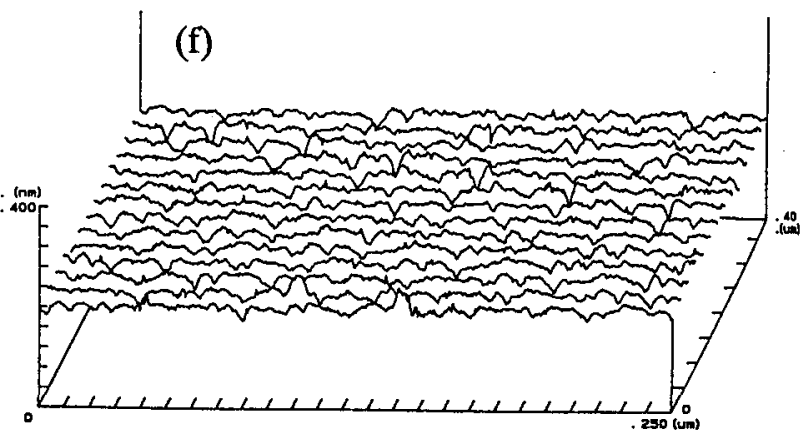

Fig.1 Three-dimensional surface profiles of the disks (a) coated with barium ferrite, (b) coated with $\alpha-\mathrm{Fe},(\mathrm{c})$ coated with $\mathrm{Co}-\gamma-\mathrm{Fe}_{2} \mathrm{O}_{3}$, (d) sputtered with $\mathrm{Co}-\mathrm{Pt}-\mathrm{Ni}$, (e) sputtered with $\mathrm{Co}-\mathrm{Ni}-\mathrm{Cr}$ and (f) plated with $\mathrm{Co}-\mathrm{Ni}-\mathrm{P}$. 
Table 3. The surface roughness of the disks

\begin{tabular}{|c|c|c|c|c|c|c|}
\hline & $\begin{array}{l}\text { Bariua } \\
\text { Perrite }\end{array}$ & $\alpha-\mathrm{Fe}$ & $\begin{array}{l}\mathrm{CO}_{0}-\gamma \\
\mathrm{Pe}_{2} \mathrm{O}_{3}\end{array}$ & $\mathrm{C}_{0}-\mathrm{Pt}-\mathrm{Hi}$ & $\mathrm{C}_{0}-\mathrm{Ni}-\mathrm{Cr}_{\mathrm{r}}$ & \multirow{2}{*}{\begin{tabular}{|c|}
$\mathrm{Co}^{-} \mathrm{Ni}-\mathrm{P}$ \\
Plated
\end{tabular}} \\
\hline & \multicolumn{3}{|c|}{ Coated } & \multicolumn{2}{|c|}{ Sputtered } & \\
\hline $\mathrm{Ra}$ a A $)$ & 35 & 33 & 147 & 71 & 68 & 55 \\
\hline$R \max (A)$ & 638 & 525 & 4850 & 1150 & 1069 & 813 \\
\hline
\end{tabular}

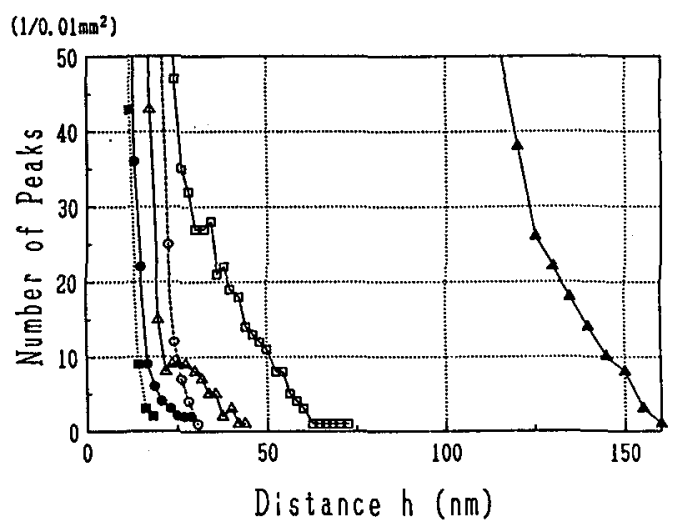

Fig. 2 The number of the peaks on the plane with distabce, $h$, above the mean plane for the disks coated with barium ferrite (-- - ), coated with $\alpha-$ $\mathrm{Fe}(----)$, coated with $\mathrm{Co}-\gamma-\mathrm{Fe}_{2} \mathrm{O}_{3}(--\mathrm{A}--)$, sputtered with $\mathrm{Co}-\mathrm{Pt}-\mathrm{Ni}(--\mathrm{O}--)$, sputtered with $\mathrm{Co}-\mathrm{Ni}-\mathrm{Cr}(--\square--)$ and plated with $\mathrm{Co}-\mathrm{Ni}-\mathrm{P}$ $(--\Delta--)$.

plane with the distance, $h$, above the mean plane. The peaks of the $\mathrm{Co}-\gamma-\mathrm{Fe}_{2} \mathrm{O}_{3}$ disk is higher and much more than those of the others. As shown in fig.2, the number of the peaks of our specimen decreases more steeply compared with the thin film media.

In thin film media, the surfaces are affected by the shapes of the substrates which have texturing treatment. On the other hand, in case of the particulate media, the surface roughness of the magnetic layer can be more improved by the polishing treatment than that of the substrate. Therefore, the media with a much more smooth surface were obtained in this work.

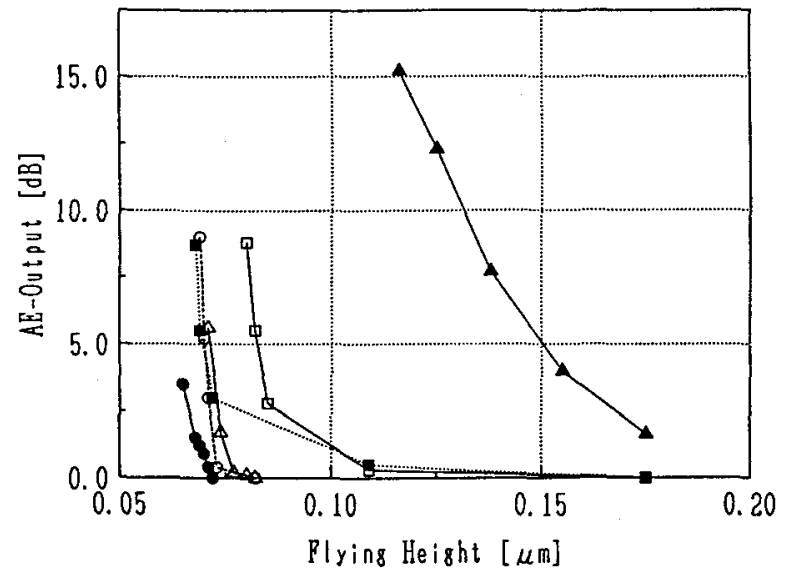

Fig.3 Head-Fly-Height characteristics for the disks coated with barium ferrite (-- $)$, coated with $\alpha-$ $\mathrm{Fe}(---)$, coated with $\mathrm{Co}-\gamma-\mathrm{Fe}_{2} \mathrm{O}_{3}(--\mathrm{A}--)$, sputtered with $\mathrm{Co}-\mathrm{Pt}-\mathrm{Ni}(--\mathrm{O}--)$, sputtered with $\mathrm{Co}-\mathrm{Ni}-\mathrm{Cr}\left(--\square^{-}\right)$and plated with $\mathrm{Co}-\mathrm{Ni}-\mathrm{P}$ $(--\Delta--)$.

Table 4. The value of $D_{50}$ for the disks

\begin{tabular}{|c|c|c|c|c|c|c|}
\hline & $\begin{array}{l}\text { Bariua } \\
\text { Ferrite }\end{array}$ & $\alpha-F e$ & $\begin{array}{l}\mathrm{CO}-\gamma \\
\mathrm{Fe}_{2} \mathrm{O}_{3}\end{array}$ & $\mathrm{C}_{0}-\mathrm{Pt}-\mathrm{Ni}$ & $\mathrm{Co}-\mathrm{Ni}-\mathrm{Cr}$ & $\mathrm{Co}_{0} \mathrm{Ni}-\mathrm{P}$ \\
\hline & \multicolumn{3}{|c|}{ Coated } & \multicolumn{2}{|c|}{ Sputtered } & Plated \\
\hline$D_{58}(k F C I)$ & 41.7 & 38.2 & 24.0 & 39.5 & 34.9 & 36.3 \\
\hline
\end{tabular}

\section{2) Head-Fly-Height Characteristics}

Fig.3 shows Head-Fly-Height characteristics of the disks [2]. In this figure, the outputs from an AE-sensor (Acoustic Emission sensor) mounted on the head slider are plotted against the flying height. In the produced disks, the rapid increase of the AEoutput was not observed over $0.07 \mu \mathrm{m}$, which made flying height less than $0.1 \mu \mathrm{m}$. The thin film media also have good Head-Fly-Height characteristics. While, the $\mathrm{Co}-\gamma-\mathrm{Fe}_{2} \mathrm{O}_{3}$ can not be used less than 0.2 $\mu \mathrm{m}$ of the flying height.

The result of Head-Fly-Height is consist with that of fig.2. 


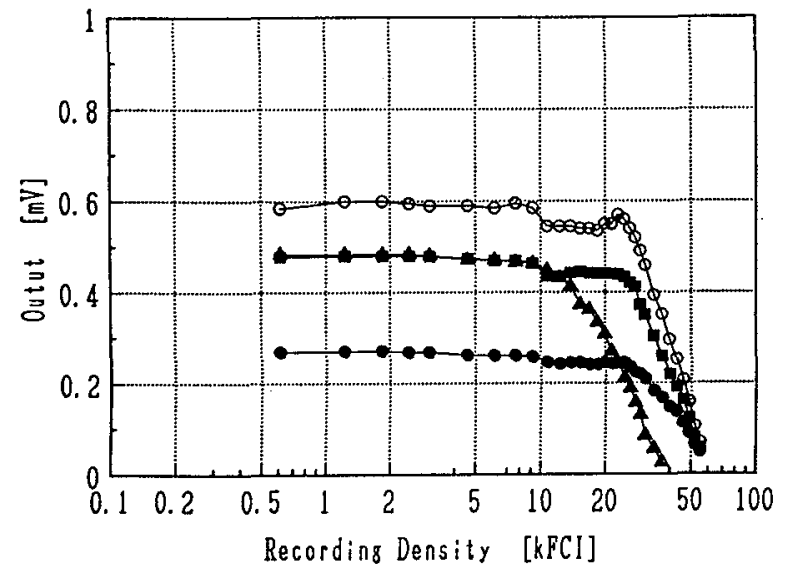

Fig.4A Recording density characteristis using MIG head for the disks (a) coated with barium ferrite $(---)$, (b) coated with $\alpha-\mathrm{Fe}(----)$, (c) coated with $\mathrm{Co}-\gamma-\mathrm{Fe}_{2} \mathrm{O}_{3}\left(--\mathrm{A}_{-}-\right)$and (d) sputtered with $\mathrm{Co}-\mathrm{Pt}-\mathrm{Ni}(--\mathrm{O}--)$.

\section{Recording Density}

The measurement was carried out by a MIG head (Sendust, G/L;0.52 $\mu \mathrm{m}, \mathrm{T} / \mathrm{W} ; 12.0 \mu \mathrm{m}$ and $\mathrm{F} / \mathrm{H} ; 0.13 \mu \mathrm{m}$ ) and a thin film head (Permalloy, $\mathrm{G} / \mathrm{L} ; 0.32 \mu \mathrm{m}, \mathrm{T} / \mathrm{W} ; 13.0 \mu \mathrm{m}$ and $\mathrm{F} / \mathrm{H} ; 0.097 \mu \mathrm{m})$

Table 4 shows the value of $D_{50}$. The barium ferrite disk and the Co-Pt-Ni disk had higher recording density. Both of the high coercivity and the high $\mathrm{S}^{*}$ of these media may contribute to these short wavelength recording properties.

The profiles of recording density characteristics are shown in fig.4A using the MIG head and in fig.4B using the thin film head. The barium ferrite disk, however, shows fairly low output than thin film media and $\alpha-\mathrm{Fe}$ disk.

The $\mathrm{Co}-\gamma-\mathrm{Fe}_{2} \mathrm{O}_{3}$ disk was measured by a higher flying height head $(\mathrm{F} / \mathrm{H}=0.24 \mu \mathrm{m})$.

\section{O/W, Noise and Bit-Shift Characteristics}

$\mathrm{O} / \mathrm{W}$ (Over Write), noise and bit-shift were measured by a head used in 2 . The recording frequency $(2 \mathrm{~F})$ was $5 \mathrm{MHz}$.

Fig.5 shows the dependence of $\mathrm{O} / \mathrm{W}$ on recording density. As shown in fig.5, these high coercivity disks had the bottoms at recording density about $40 \mathrm{kFCI}[3,4]$. The barium ferrite and $\alpha-\mathrm{Fe}$ particulate disks and thin film disks had sufficient $\mathrm{O} / \mathrm{W}$

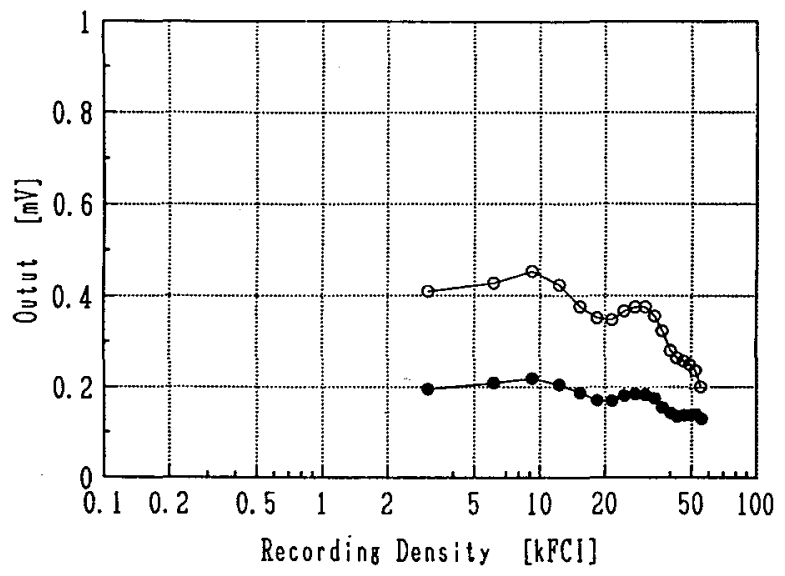

Fig.4B Recording density characteristis using thin film head for the disks (a) coated with barium ferrite $(---)$, (b) sputtered with $\mathrm{Co}-\mathrm{Pt}-\mathrm{Ni}(--\mathrm{O}--)$.

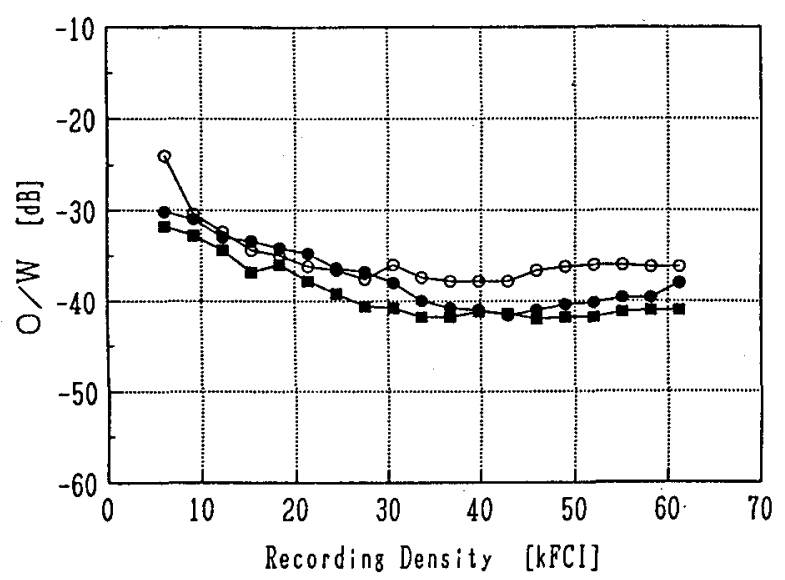

Fig.5 The dependence of $\mathrm{O} / \mathrm{W}$ on recording density using MIG head for the disks (a) coated with barium ferrite (-- $)$, (b) coated with $\alpha-\mathrm{Fe}(---)$ ) and (c) sputtered with $\mathrm{Co}-\mathrm{Pt}-\mathrm{Ni}(--\mathrm{O}--)$.

Table 5. The Bit-Shift of the disks

\begin{tabular}{|l|c|c|}
\hline & $\begin{array}{l}\text { Barium } \\
\text { Ferrite } \\
\text { Coated }\end{array}$ & $\begin{array}{l}\text { Co-Pt-Ni } \\
\text { Sputtered }\end{array}$ \\
\hline B S F (ns) & 7.55 & 5.00 \\
\hline B S B 8 (ns) & 11.90 & 10.00 \\
\hline
\end{tabular}




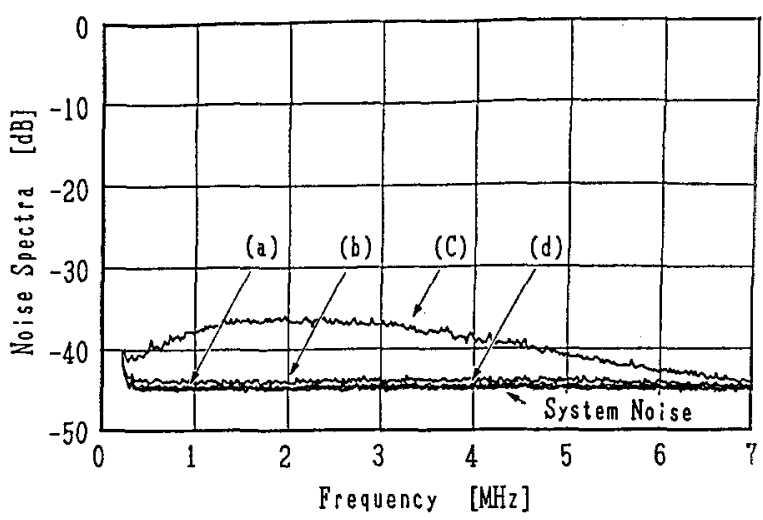

Fig.6 DC eraced noise spectra using thin film head for the disks (a) coated with barium ferrite, (b) coated with $\alpha-\mathrm{Fe}$, (c) coated with $\mathrm{Co}-\gamma-\mathrm{Fe}_{2} \mathrm{O}_{3}$ and (d) sputtered with $\mathrm{Co}-\mathrm{Pt}-\mathrm{Ni}$.

characteristics at more than $30 \mathrm{kFCI}$.

The DC erased noise spectra of each specimen is shown in fig.6. The noise level of the produced disk with barium ferrite is the same as that of a thin film type. And the $\alpha-F e$ disk had higher noise level than the barium ferrite media. It is thought that the barium ferrite disk has higher $S^{*}$ than the $\alpha-$ Fe disk.

The bit-shift of the disks coated with barium ferrite and sputtered thin film disk were measured. The results are shown in table 5. The FF pattern of the barium ferrite disk is large, owing to its low $2 \mathrm{~F}$ output. The peak-shift of that disk, however, is smaller than that of thin film type.

\section{Reliability}

CSS (contact-start-stop) tests of the produced disks were carried out with a composite calcium titanate head. The rotational speed was $3600 \mathrm{rpm}$. And the loading weight of the head was $15 \mathrm{~g}$ and the flying height was $0.28 \mu \mathrm{m}(\mathrm{v}=8.3 \mathrm{~m} / \mathrm{sec})$. The result is shown in fig.7. The particulate disks achieved lower friction and more cycles than thin film types. The friction coefficient of the produced disk was lower than that of a $\mathrm{Co}-\gamma-\mathrm{Fe}_{2} \mathrm{O}_{3}$ disk, which was 0.24 after 20,000 cycles. On the other hand, the coefficients of the frictions of thin film disks with carbon protected layers increased in small counts of CSS cycles. And the thin film disk failed with the wear-out of the magnetic layer or stopped by sticking of the head to the disks.

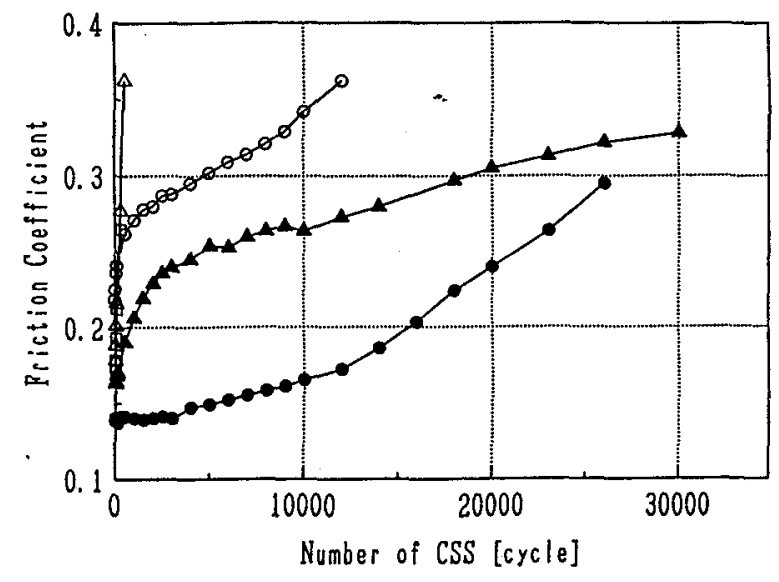

Fig.7 CSS durability for the disks coated with barium ferrite (--- ) , coated with $\mathrm{Co}-\gamma-\mathrm{Fe}_{2} \mathrm{O}_{3}$ $(--\mathrm{A}-\mathbf{-})$, sputtered with $\mathrm{Co}-\mathrm{Pt}-\mathrm{Ni}(--\mathrm{O}--)$, sputtered with $\mathrm{Co}-\mathrm{Ni}-\mathrm{Cr}\left(--[--)\right.$ and plated with $\mathrm{Co}^{-}$ $\mathrm{Ni}-\mathrm{P}\left(--\Delta^{--}\right)$

It is supposed that the particulate media could contain more lubricant in the porous structure of the magnetic layer than that of thin film disks. Therefore, the particulate disk must have shown more excellent durability.

\section{CONCLUSION}

We described the high smooth and high coercivity characteristics rigid disks with barium ferrite and $\alpha-\mathrm{Fe}$ magnetic particles. The disks achieved low flying height less than $0.1 \mu \mathrm{m}$ and high recording density more than $30 \mathrm{kFCI}$ was obtained. The characteristics of friction and CSS durability of the disks were much better than those of the other types and satisfied the fundamental characteristics of high density rigid disks.

\section{REFERENCE}

[1] T.Ido, O,Kubo and H.Yokoyama, IEEE Trans. Magn., MAG-22, pp704,1986

[2] Y.Hatamura et al., IEEE Trans. Magn., MAG24, pp2638, 1988

[3] K.Yokoyama et al., IEICE Technical Report (Japan), MR89-36, pp25,1989

[4] D.Wachenschwanz and F.Jeffers, IEEE Trans. Magn., MAG-21, pp1380, 1985 